Article

\title{
Automated Mapping of Historical Native American Land Allotments at the Standing Rock Sioux Reservation Using Geographic Information Systems
}

\author{
Joshua Jerome Meisel ${ }^{1, *} \mathbb{(}$, Stephen L. Egbert ${ }^{2} \mathbb{D}$, Joseph P. Brewer $\mathrm{II}^{3}$ and Xingong $\mathrm{Li}^{2}$ \\ 1 Natural and Social Sciences, Haskell Indian Nations University, 155 Indian Avenue, Lawrence, KS 66046, USA \\ 2 Geography and Atmospheric Science, University of Kansas, 1475 Jayhawk Boulevard, \\ Lawrence, KS 66045, USA; segbert@ku.edu (S.L.E.); lixi@ku.edu (X.L.) \\ 3 Environmental Studies, University of Kansas, 2100 Jayhawk Boulevard, Lawrence, KS 66045, USA; \\ joseph.brewer@ku.edu \\ * Correspondence: jmeisel@haskell.edu
}

\section{check for} updates

Citation: Meisel, J.J.; Egbert, S.L.; Brewer, J.P., II; Li, X. Automated Mapping of Historical Native American Land Allotments at the Standing Rock Sioux Reservation Using Geographic Information Systems. ISPRS Int. J. Geo-Inf. 2021, 10, 183. https://doi.org/10.3390/ ijgi10030183

Academic Editors: Wolfgang Kainz and Fraser Taylor

Received: 18 February 2021

Accepted: 18 March 2021

Published: 20 March 2021

Publisher's Note: MDPI stays neutral with regard to jurisdictional claims in published maps and institutional affiliations.

Copyright: (c) 2021 by the authors. Licensee MDPI, Basel, Switzerland. This article is an open access article distributed under the terms and conditions of the Creative Commons Attribution (CC BY) license (https:// creativecommons.org/licenses/by/ $4.0 /)$.

\begin{abstract}
The General Allotment Act of 1887, also known as the Dawes Act, established the legal basis for the United States government to break up remaining tribally-owned reservation lands in the U.S. by allotting individual parcels to tribal members and selling the remaining "surplus." This research explores the processes involved in mapping these historical allotments and describes a method to automatically generate spatial data of allotments. A custom geographic information systems (GIS) tool was created that takes tabular based allotment land descriptions and digital Public Land Survey (PLSS) databases to automatically generate spatial and attribute data of those land parcels. The Standing Rock Sioux Tribe of North and South Dakota was used as the initial study area to test the mapping technique, which resulted in successfully auto-mapping over $99.1 \%$ of allotted lands on the reservation, including the smallest aliquot parcels. This GIS technique can be used to map any tribal lands or reservation with allotment data available, and currently it can be used to map over 120 individual reservations using publicly available data from the Bureau of Land Management (BLM).
\end{abstract}

Keywords: Dawes; allotment; GIS; map; automation; PLSS; geographic information systems; reservation; indigenous; Standing Rock

\section{Introduction}

The Standing Rock Sioux Reservation located, along the border of North and South Dakota, has undergone major disruptive changes in land tenure over the past 150 years (Figure 1). Standing Rock, originally a part of the Great Sioux Reservation established in the Fort Laramie Treaty of 1868, is the seventh largest Indian reservation in the United States (3572 sq. mi., 9251 sq. km.), yet has one of the highest poverty rates of anywhere in the country [1]. Despite the vast tracts of land and resources within the reservation, tribal members still experience the consequences of historic decisions made far away in both space and time.

\subsection{The Dawes Act and Land Allotment}

The biggest contributor to the ongoing land issues on the reservation was the Dawes Act, also known as the General Allotment Act of 1887 [2]. This Act of Congress forced allotment in severalty on tribal members residing on reservations, meaning that tribes as a whole no longer owned their reservation land; instead, individual tribal members received their own parcels of land, known as allotments. The remaining unassigned lands were deemed "surplus" and sold on the open market, most often to white settlers. 


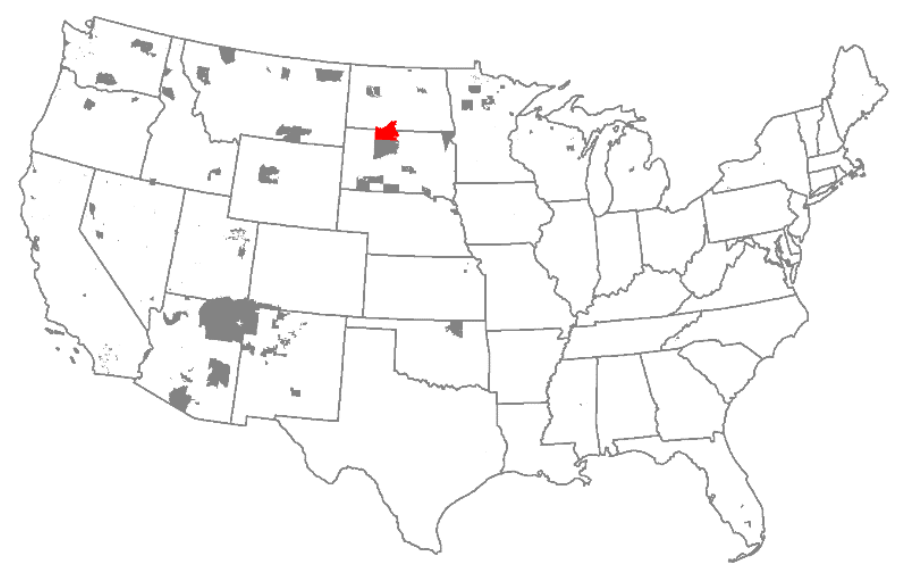

Figure 1. Map of American Indian reservations in the contiguous United States. The Standing Rock Sioux reservation is highlighted in red. Data source: U.S. Census Bureau Federal American Indian Reservations (AIR).

Reformers and federal officials promoted land allotment as a progressive step towards the civilization and assimilation of American Indians as farmers and ranchers. However, the Dawes Act was not solely a process of giving Indians private ownership of their land; it was a way to break up the reservation, destroy tribal ideologies of land held in common, weaken the authority of tribal leaders and traditions, and open unallotted reservation lands for white settlement. Theodore Roosevelt described allotment as a "mighty pulverizing engine to break up the tribal masses" [3]. During allotment, traditional practices and patterns of land tenure were replaced by the efficient but relentless rectangular grid of the U.S. Public Land Survey System (PLSS). Allotment further tightened the legally binding relationship between the federal government and tribal nations, designating the federal government as the fiduciary and authority of tribal trust assets stemming from treaties, lands, and all tribal resources. This is known as the trust responsibility, which is carried out by the Department of Interior within the Executive Branch of the federal government of the United States.

Under the terms of the Dawes Act, heads of household received 160 acres of land, single persons over age 18 and orphans under 18 received 80 acres, and children under 18 received 40 acres. It is notable that married women were not awarded allotments, although widowed and divorced women qualified to receive allotments as heads of household. Actual parcel sizes and allotment provisions varied from reservation to reservation, depending on such factors as the amount of land available, the climate (allotments in arid regions were often larger), access to water, timber and other resources, and political considerations, including requests from the tribes themselves. In some cases, a person's allotment consisted of a single rectangular parcel containing the entire acreage to which the person was entitled; in other cases, a single allotment might consist of several different parcels, sometimes not even adjacent to each other.

Allotment had and continues to have lasting effects for American Indians in three significant ways [4]. (1) Land loss. In total, over the course of 47 years, from 1887 when the Dawes Act was instituted until its repeal under the Indian Reorganization Act in 1934, an estimated 90 to 120 million acres of land left Indian hands by a variety of means, including sale of surplus reservation lands, fraud, and sales of land by individual allottees. (2) Fractionation. The Dawes Act failed to provide for what would happen to an allotment parcel when its owner died; thus, upon the death of an allotee who died without a will, title to the land went to his or her heirs according to the laws of the state in which the land was located. When this was repeated over several generations, the number of owners easily reached dozens to sometimes hundreds, all of whom held undivided interests to a fraction of the original parcel. This problem is commonly referred to as fractionation or the heirship problem and is the subject of numerous ongoing legal and policy proceedings $[5,6]$. 
For example, it is not uncommon for an individual Indian land owner to have as little as $1 / 4000$ th of an undivided interest in a parcel of land. Furthermore, it is often the case that a person may have fractional ownership interests in a number of different land parcels, sometimes scattered over several reservations, because of the residence locations and intermarriage of that person's ancestors. (3) Checkerboarding. The post-allotment influx of white settlers onto reservations in many cases created patterns of interspersed parcels owned or operated by white settlers, a pattern known as checkerboarding. Advocates of allotment actually viewed this pattern as desirable because they assumed that Indian allotment holders would benefit by observing the agricultural practices of their white neighbors. In fact, it disrupted existing agricultural, living, and social patterns, thereby further diminishing traditional ways of life.

\subsection{Research Context}

The allotment era of American Indian history is a well-covered topic, as numerous articles and books have been published on the subject, ranging in scale from the national [4,7-10], to state and regional areas [11-13], to individual tribes [14,15]. Allotment has been explored from political, historical, social, and legal perspectives, but relatively few studies have explored allotment from a spatial perspective. Imre Sutton, the late professor emeritus of Geography at California State University, was one of the first academics to make a national call for more work to examine the vastness and irregularity of the cartographic record for Indian lands. While there exist many maps of Indian lands, Sutton questioned the veracity of land ownership maps as it is "hard to ascertain how accurate field maps at BIA or tribal offices are today, and the published record gets out of date very quickly" [16]. If studies of allotment and the consequences of this failed policy are to be seriously examined, there exists a need for a method to be able to generate, synthesize, and analyze allotment information.

In the past, a major problem with geographic research on Indian allotments has been the lack of readily available spatial data for land surveys and allotments, as well as reliable and accessible digital sources of these datasets. Previous allotment mapping has largely been done by hand, either with traditional cartographic ink-on-paper methods or by manually digitizing paper maps or photographic images using GIS software and adding attribute data from archival allotment records. One of the earliest geographers to map and analyze land tenure patterns on a reservation was Dr. Harold Hoffmeister, of the University of Colorado Boulder in 1945, who studied the disparities in land tenure on the Consolidated Southern Ute Reservation in Colorado and Utah [17]. Later, in 1985, John Hartwell Moore performed an early spatial analysis of allotments among the Cheyenne in Oklahoma [18]. He utilized allotment records to manually map land ownership of the Cheyenne and used that dataset to analyze social connections within tribal groups using census information.

In the early years of the twenty-first century, several studies used manual methods to digitize maps and allotment records for use in GIS analysis. Middleton [19] analyzed historical allotments of former Maidu reservation lands in northern California utilizing National Archives and local county records to trace land ownership for the Mountain Maidu in Plumas County, California. She manually constructed spatial features of allotments using GIS to follow the historical lineage of land ownership of original Maidu allotted lands. Greenwald, in her comparative studies of the experiences of the Nez Perce, Jicarilla Apache, and Cheyenne River Sioux tribes, analyzed allotment era land maps and employed a manual digitizing technique to generate spatial data of allotments in GIS [14,20]. Greenwald has noted the difficulties and limitations of manually digitizing allotments, as well as obstacles presented by a lack of data for some reservations of interest [21]. Palmer later employed a mixture of manual digitization of historical maps as well as modern land ownership data obtained from tribal offices of the Kiowa tribe of Oklahoma to examine the loss of Kiowa allotment lands [22]. Kretzler and the Grand Ronde Land Tenure Project developed GIS data for allotments at the Grand Ronde reservation in Oregon $[23,24]$. 
Working with the Grand Ronde tribal Historical Preservation Organization, the team was able to retrieve and digitize maps and other archival documents of historical land tenure on the Grand Ronde reservation to create a digital database of land allotments for visualizing allotment patterns and understanding the loss of allotment lands

All of these previous allotment studies utilized manual methods to generate maps and, in the more recent studies, to create GIS spatial data of Indian lands. However, within approximately the past five years, the public availability of accurate and detailed digital datasets for the Public Land Survey System (PLSS) has created the potential for detailed mapping of Indian land allotments, and several recent studies have demonstrated the utility of these datasets in combination with the analytical capabilities of GIS. Egbert and Smith used a commercial software extension for ArcGIS to map and explore Kickapoo allotments in Kansas using a digital PLSS database and allotment records transcribed from archival records [25]. They found that allotment selections were primarily located in fertile stream bottomlands and their associated riparian woodlands. Allen used the same method to map and analyze allotments on the Omaha Reservation in Nebraska, finding that allotment preferences varied between groups of tribal members who favored adhering to traditional values, choosing allotments near traditional village locations, and those who saw advantage in taking allotments adjacent to future railroad lines because of their access to markets [26]. Sun Eagle likewise used the digital PLSS and archival allotment records for visualizing allotments on the Pawnee Reservation in Oklahoma [27]. She discovered that family and clan relationships were reflected in spatial patterns of allotment selections and that, as Egbert and Smith had found, there was an overall strong preference for fertile stream bottoms and woodlands.

Most recently, Dippel and colleagues in several studies utilized a different technique to map Indian lands by using digital Indian land records obtained from the Bureau of Land Management (BLM) General Land Office (GLO) online database and matching them to PLSS quarter-section 160-acre units [28-31]. The major advancement made by Dippel et al. was the use of the two digital databases in tandem to match allotments to land descriptions. This avoided the team having to perform map digitization, archival work, or having to purchase additional software extensions for an already expensive software package. Their method, however, did not actually map allotment parcels of less than one quarter-section (160 acres) in size, of which there are many, but rather assigned them to the quarter section to which they belong. This was adequate for the broad-scale analyses they performed but does not permit analysis at the fine scale required for exploring numerous specific questions on individual reservations.

\subsection{Mapping Allotment at Standing Rock}

An act of the Fiftieth Congress in 1889 authorized the president to direct that the Standing Rock Reservation be surveyed and that allotments in severalty be granted to its residents, as follows: one half-section (320 acres) to heads of family; one quarter-section to single persons over age 18 and orphan children under 18; and one eighth-section (80 acres) to children under 18 [32]. Two features of the enabling act are noteworthy: first, the allotment sizes were twice the size of those stipulated in the Dawes Act, likely due to the arid climate and the amount of land available, and second, as in the original Dawes Act, married women were not authorized to receive allotments. However, the Fifty-Ninth Congress (1906-1907) subsequently granted allotments to married women and to children who had not previously been allotted [33]. (These allotments were made after the initial allotments under the terms of the 1889 Act were completed.) Actual allotment did not begin at Standing Rock until 1906 with the appointment of Special Allotting Agent Carl Gunderson. The vast majority of allotments were completed by 1910, but additional allotments continued to be made up through 1934. In all, 4726 persons at Standing Rock received allotments, consisting of a total of 13,324 parcels. In addition, because of the scarcity of timber on the reservation and its value for fuel and construction, small timber allotments, generally of 2.5 to 10 acres in size, also were made. 
This project began in 2016 with funding from the Indian Land Tenure Foundation (and later from the University of Kansas General Research Fund). The overall goal was to explore the feasibility of using the information in land allotment ledgers to create a digital spatial database of allotments on the Standing Rock Reservation to use as the basis for visualizing and exploring patterns of allotment.

In the first phase of the project, information from the Standing Rock archival allotment records was manually transcribed into Excel spreadsheets and then ingested into an ArcGIS add-in tool that used a digital database of the Public Land Survey (PLSS) at the section level to create a spatial database of all allotments that consisted of standard subdivisions (aliquots), e.g., quarter sections, half sections, quarter-quarter sections, and so on). Non-standard parcels such as government lots could not be mapped by the add-in program and subsequently were added manually. Although this method produced a map that showed the overall pattern of allotments and permitted exploration of the spatial data, we discovered two major problems with the process. The first was the time-consuming, expensive, and error-prone nature of the transcription process itself. Hundreds of labor hours were required to enter and cross check the thousands of allotments and their associated attribute data. Even after the cross-checking process, numerous errors in transcription were discovered, necessitating additional reference to the original ledger sheets and the online General Land Office database created by the Bureau of Land Management (which itself was being updated during the course of the project) in order to make corrections. The second problem was that the add-in parcel subdivision tool created thousands of duplicate lines and vertices in the output map, which were frequently offset from each other. This was because each allotment parcel, with its topology, was created independently of all the other parcels, including its neighbors. This was in addition to the program's inability to handle non-standard aliquots and government lots, as noted above. The net result was that additional large inputs of labor were needed to correct the underlying spatial database of allotments.

Although the methodology in the initial phase of the project ultimately produced a largely accurate map of allotments at Standing Rock, it was apparent that a more efficient and accurate mapping method was needed, one that could take advantage of the digital databases rapidly coming online to produce allotment maps of reservations in a few days, rather than weeks or months. Thus, the next phase of the project focused on the development of the tool described in this paper.

\subsection{Goals}

Digital allotment mapping using GIS is critical because it provides the cartographic visualization and spatio-analytical capabilities to explore both the patterns and processes of allotment. These are important not merely for satisfying historical curiosity but for providing a background for investigating and understanding subsequent events and impacts down to the present. The new allotment mapping tool fills the gaps in previous methods by developing a technique in which Indian allotments can be automatically mapped in a GIS software environment using common GIS tools and publicly available spatial databases and land allotment data. This new method generates complete and accurately sized and shaped GIS data of nearly all Indian allotments down to the finest scale. These GIS methods and techniques are repeatable and re-creatable in other GIS software; however, it was designed to be used in tribal offices on the reservation where ESRI's ArcGIS is the standard software. This method is intended specifically to automate the process of mapping historical allotments on Indian reservations, but it can also be used by anyone wanting to map land property descriptions recorded in PLSS format. These tools are explained and preliminary allotment datasets are open-source and will be available at www.haskellgeography.com (accessed on 18 March 2021). 


\section{Materials and Methods}

\subsection{Data Sources}

We used two major data sources in this study: historical allotment data extracted from handwritten allotment ledger books and digital spatial data for the Public Land Survey System. The nature of each of these datasets and the means of obtaining them are described below.

\subsubsection{Allotment Data}

Tribal allotment data are openly available from at least two different sources. The Bureau of Land Management stores copies of the original allotment ledger books for many reservations in their various district offices, as does the National Archives at both its headquarters location in Washington, DC and branches located across the country. For the Standing Rock reservation, allotment ledger books are located at the National Archives branch in Kansas City.

Allotments were recorded in two types of ledger books, generally known as Tract Books and Allotment Registers, and several copies of each were made at the time of allotment. Both types of allotment ledgers contain both spatial and attribute data: the spatial data consist of the legal description of allotment parcels in PLSS format, while the attribute data contain information about each allottee, such as name, age, and gender. Tract books, as their name implies, were organized geographically according to the rectangular Public Land Survey System. In this case, the legal description of the land came first, followed by the allottee's name and allotment number and sometimes other information. Allotment registers, on the other hand, were organized by allotment number in numerical order (the first allottee being number 1, and so on). Information generally included, in addition to allotment number, the allottee's name (both "English" name and "Indian" name), age, marital status, and gender, and sometimes the relationship of the allottee to the head of household. This information was followed by the legal description of the parcel(s) making up the person's allotment and the total acreage allotted. For this study, high-resolution photographs of the Standing Rock allotment register and timber allotment register were made at the Kansas City Branch of the National Archives for subsequent transcription into Excel spreadsheets for use in conjunction with the PLSS to create a GIS database of allotments.

In addition to the original handwritten allotment ledgers, allotments now can also be mapped using digital allotment data available from the Bureau of Land Management (BLM) General Land Office (GLO) online database (hereafter referred to as the BLM/GLO database). The BLM/GLO data, transcribed from original allotment records, are already in a digital tabular format that only needs slight modification to prepare for mapping with GIS software. However, the BLM/GLO dataset lacks the additional social/demographic information (age, gender, family relationships) available in the archival allotment ledgers. The full BLM/GLO digital allotment data for Standing Rock only became available after we had transcribed the handwritten allotment register, but we found it highly useful in the later stages of this project. We were able not only to compare the nature and value of each of the datasets, but also to supplement the incomplete allotment register data with the BLM/GLO digital data, as we note below.

\subsubsection{Digital Land Survey Data}

The Public Land Survey System (PLSS) or Rectangular Survey System is a system for surveying and dividing land for settlement and sale and is the dominant land description system in the majority of the U.S., primarily in areas west of the Appalachian Mountains, although there are notable exceptions, especially in areas originally settled under French or Spanish colonial authority. The PLSS is a popular source of historical information used by researchers to investigate various topics, such as exploring historical cultural landscapes [34]. It also has been used as a base layer in several of the previously discussed allotment mapping studies. However, in a larger sense the PLSS grid ultimately changed 
the way Indigenous people tenured their lands under the evolving land systems in the United States. The insatiable desire of Euro-Americans for additional land further opened up Indian lands to settlers, squatters, and speculators. Survey grids like the PLSS that were used in this process are problematic to many Indigenous people, since they overlaid a rigorous grid system of land division over already existing Native systems of land tenure, occupation, and use. They therefore represent one of the methods by which land was explored, partitioned, and obtained from Native peoples [35]. It is a harsh reminder, and for many Native people a tangible representation, of the methods used to disenfranchise, marginalize, and assimilate them, the effects of which are still present.

As a survey system, the PLSS splits much of the US into a massive grid of squares (Figure 2). At the largest scale there are township and range lines which create 6 by 6 square mile grids across the landscape. Within these townships the PLSS has smaller 1 square-mile units called sections. Each section is further divided into quarter sections and quarterquarter sections; these various regular divisions of a section are called aliquots. In addition to standard aliquot units, there are government lots, which are generated where the grid is slightly altered to compensate for errors that occur when laying a 2-dimensional grid on top of the 3-dimensional Earth, or where the grid meets the meander of a river or shoreline of a lake.

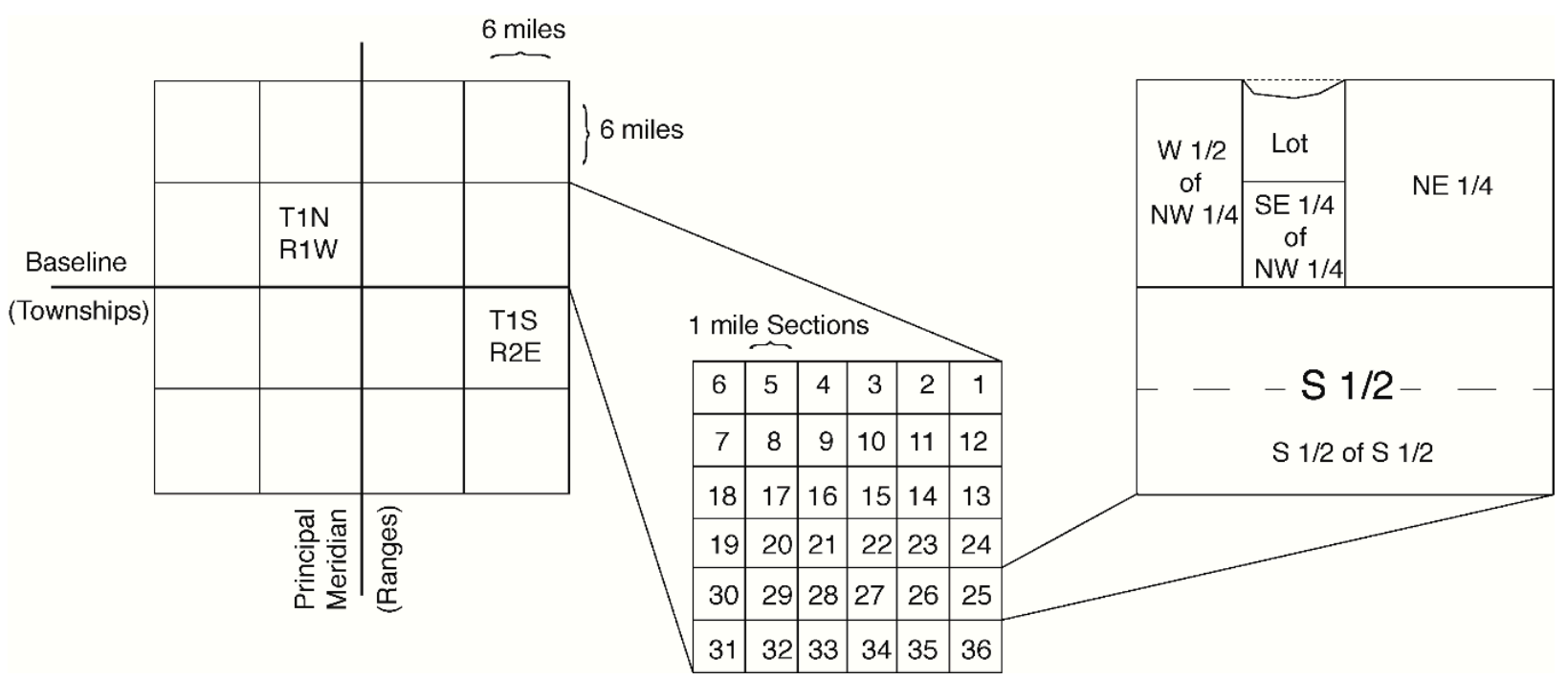

Figure 2. Public Land Survey System (PLSS) structure and aliquot examples.

The PLSS is available in digital format from the FGDC Cadastral Subcommittee Outreach Web Site (www.nationalcad.org) in both shapefile and geodatabase formats. The PLSS datasets come in multiple different layers, based on the size of the grid subdivisions. The "second division" of the PLSS, referred to here as quarter-quarter sections, is the most commonly available atomic level of PLSS data, each grid square representing 40 acres. The "intersected" PLSS layer contains all quarter-quarter sections, government lots, and parcel slivers created by river meanders and bodies of water. The intersected layers are used to map allotments using the tool described here as it contains the necessary attribute data. The attribute fields of the PLSS have been standardized by the FGDC, which makes this GIS technique universal for all states with PLSS data availability. 


\subsection{Methods: Tool Development}

The implementation of the allotment mapping tool was created using ArcGIS Model Builder and involves the following four general stages. First, using the digital PLSS data, create a master aliquot spatial base layer of all possible aliquot subdivisions with unique parcel IDs (Figure 3); second, create a database of allotment parcels containing both land description data and attribute data with unique IDs for each parcel that correspond to the format for unique parcel IDs in the PLSS master aliquot database; third, merge the allotment database with the aliquot database using matching parcel IDs to create a map of allotments; and finally, map the few remaining unmapped non-standard parcels by (1) creating "micro" aliquot databases for unmapped small aliquots and merging them with the allotment database and (2) manually digitizing the few remaining allotments that could not be mapped using the tool. In the discussion that follows, we first describe the procedures followed for each step and then, where appropriate, discuss its implementation for the Standing Rock project. A schematic summary of the basic allotment mapping tool will be referred to throughout the article (Figure 4).

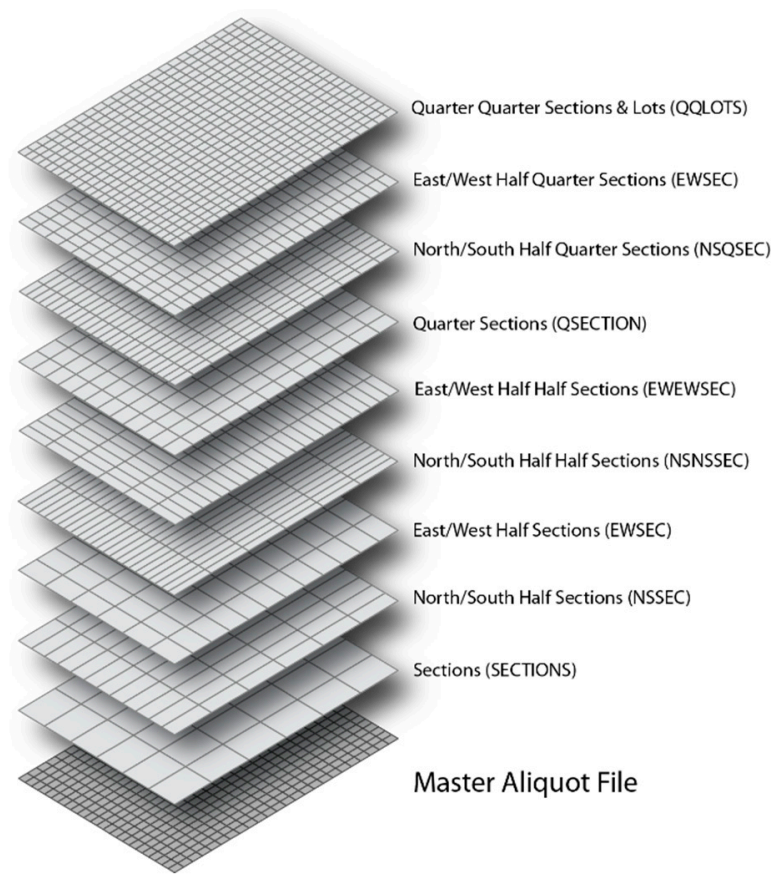

Figure 3. The "master aliquot" is a GIS data layer that contains the shapes of all possible aliquot parcels within a section merged together into one comprehensive file. Each parcel contains a Unique ID which is used by the allotment mapping tool to join the allotment spreadsheet and create the allotment parcel shapes with accompanying attribute data. 


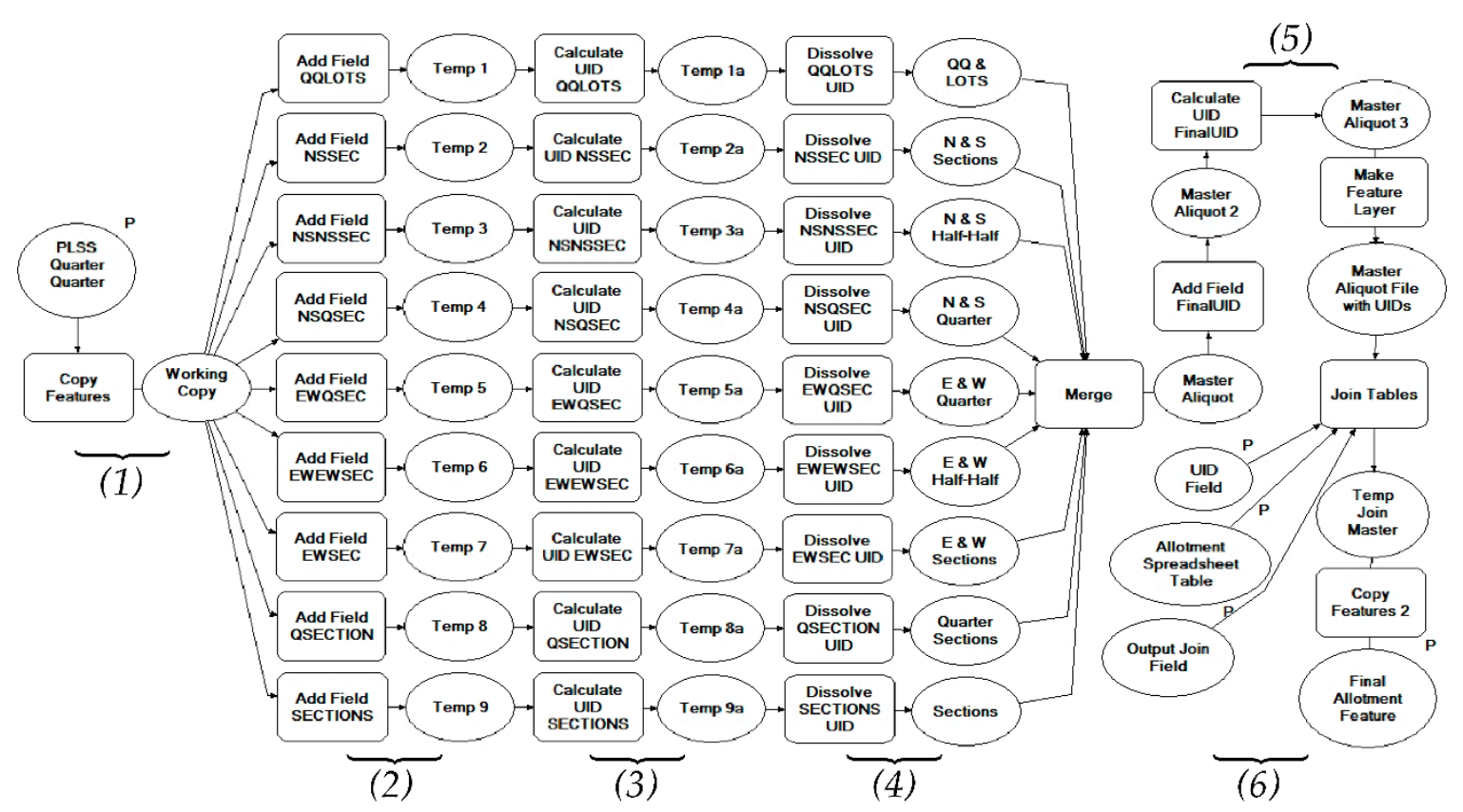

Figure 4. Schematic summary of the allotment mapping tool in ArcGIS ModelBuilder. Allotment mapping can be performed using simple and commonly available GIS processes. Step (1) create a copy of the original PLSS quarter-quarter data files. Step (2) generate new attributes fields for each class of land aliquot. Step (3) calculate the unique ID values for each type of land class. Step (4) dissolve borders of PLSS base layer polygons based on common unique ID, creating new shapes for each aliquot. Step (5) merges and concatenates the "master aliquot" file and its attributes. Step (6) joins the "master aliquot" with the tabular data of land descriptions generating the final data layer.

\subsubsection{Create the Master Aliquot Database}

The digital PLSS databases as they currently exist are useful for basic cadastral mapping and as a way to systematically identify, locate, and partition large tracts of land, but they do have two significant limitations for mapping tribal allotments. First, the digital PLSS data layers do not typically contain spatial data for anything smaller than a quarterquarter section (40 acres). Many allotment parcel units on a reservation were smaller than 40 acres, and it is essential to have these data available in order to properly and completely map a tribe's original allotments. Second, the digital PLSS layers do not make available other common land description units such as half sections (320 acres), or half-quarter sections ( 80 acres), or half of a half of a quarter-quarter section (10 acres). However, these limitations can be addressed and the PLSS can be easily manipulated within a GIS software to generate all varieties of land aliquots using simple and available techniques.

The first limitation of the digital PLSS can be solved by simply splitting the PLSS data into smaller and smaller aliquot quadrants. With GIS software this task can be performed a number of ways, effectively creating smaller grids within the base PLSS grid system (Figure 5) [36]. The second limitation of the digital PLSS can be solved by using the atomic level PLSS as "building blocks" to create different size and shape aliquots such as the "northern half of section 15" or "the western half of the southeast quarter of section 34." These complex aliquots can be generated in the GIS software by merging together adjacent base units by altering the existing PLSS attributes and dissolving interior borders between features with the same altered attribute values (Figure 6a,b). If performed systematically within a section, new spatial data representing all of the various shaped and sized aliquots by doing nothing more than grouping adjacent parcels and dissolving boundaries. 


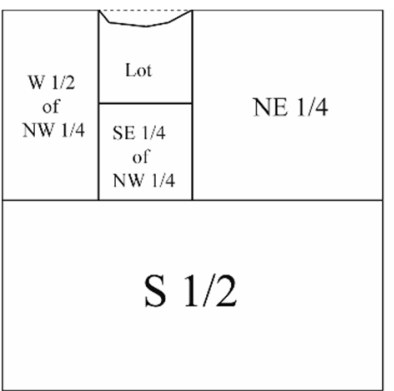

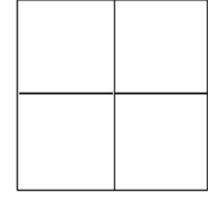

Quarter-quarter sections. 40 acre units.

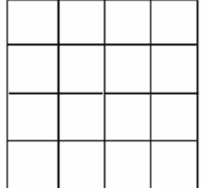

Quarter-quarterquarter sections. 10 acre units.

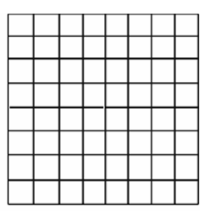

Quarter-quarterquarter-quarter sections. 2.5 acre units.

Figure 5. On the left is an example of the various PLSS-based parcel aliquots one may encounter. Quarter-quarter sections are typically the smallest sub-unit within the Public Land Survey System. Quarter-quarter sections can be quartered further using Ian Broad's Custom Grid Tools [36].

\begin{tabular}{|c|c|}
\hline NW & NE \\
\hline SW & SE \\
\hline
\end{tabular}

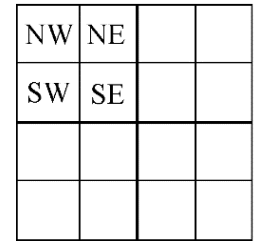

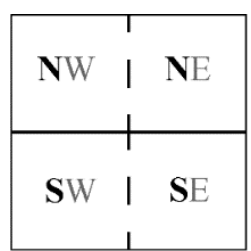

(a)

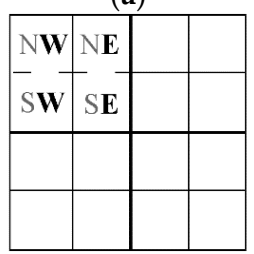

(b)
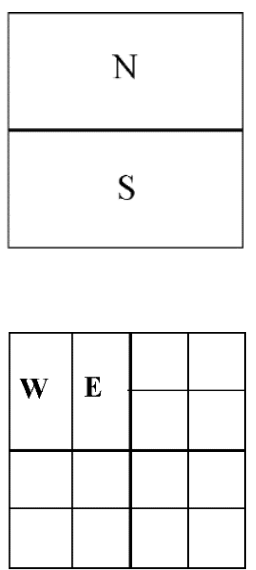

Figure 6. (a) Quarter sections are merged together to form northern and southern half sections. Removing the second string-character in the label field creates matching labels for two different Quarter Sections, northwest (NW) and northeast (NE), or southwest (SW) and southeast (SE). The Dissolve Tool uses these matching field values to combine quarter sections and generate the Half Sections. (b) The above illustrates how to generate east/west half-quarter sections, using the technique of removing string characters from the label field, in this instance the first character is removed from the label field. A Dissolve combines features with matching labels.

Creating new parcels features for the different aliquot descriptions recorded in the allotment records is only the first step. Having features to map is good, but it is the additional data recorded in the allotment ledger books that is arguably more important. The land owner's name, their age, gender and family relations are all recorded in the allotment books, and need to added to the newly created GIS features. The key to our mapping method is the ability to code each parcel in the allotment spreadsheet and each record in the PLSS base layer with matching unique identifiers (Figures 7 and 8). The unique identifiers act as addresses for individual land parcels, with each parcel having a unique string of characters used to identify, locate, and differentiate it from other parcels. These unique identifiers are essential to this mapping technique and are used for two processes in the map automation tool: first, as a way to generate a "master aliquot" file of every possible land aliquot within a section, and second, as a way to link the allotment spreadsheet data to this newly generated "master aliquot" file. We used the following terms in our databases: $\mathrm{MER}=$ prime meridian for the survey (two-digit code), $\mathrm{TWN}=$ township row number in the PLSS system (3 digits), RNG = range column number in the PLSS system (3 digits), SEC = section number within the six square mile township (2 digits), Description $=$ aliquot designation within the section, Lot $=$ government lot number within the township, if applicable. 


\begin{tabular}{|c|c|c|c|c|c|c|c|c|c|c|}
\hline \multicolumn{2}{|c|}{ SUM } & \multirow{2}{*}{$\begin{array}{c}C \\
\text { B }\end{array}$} & \multirow{2}{*}{$\begin{array}{c}\times \\
c\end{array}$} & \multirow{2}{*}{$\begin{array}{l}f_{x} \\
D \\
\end{array}$} & \multicolumn{5}{|c|}{$=$ CONCATENATE(A5,B5, C5,D5,E5,F5,G5) } & $v$ \\
\hline$\Delta$ & $A$ & & & & E & $\mathrm{F}$ & G & $\mathrm{H}$ & 1 & $\Delta$ \\
\hline 1 & State & MER & TWN & RNG & SEC & Description & Lot & UID & & \\
\hline 2 & SD & 07 & 019 & 029 & 30 & SWNE & & SD0701902930SWNE & & \\
\hline 3 & SD & 07 & 019 & 029 & 30 & SWSE & & SD0701902930SWSE & & \\
\hline 4 & SD & 07 & 019 & 029 & 30 & & & SD07019029301 & & \\
\hline 5 & SD & 07 & 019 & 029 & 30 & & 2 & $=$ CONCATENATE (A5,B5,C5,D5,E5,F5,G5) & & \\
\hline & 4 & Shee & & (†) & & & & $: 1$ & & 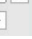 \\
\hline
\end{tabular}

Figure 7. Transcribed allotment ledger books in the spreadsheet. Concatenating land description information to generate unique IDs for each parcel. Note the similarity between the UID column in the spreadsheet with the PLSS default SECDIVID attribute field in Figure 8.

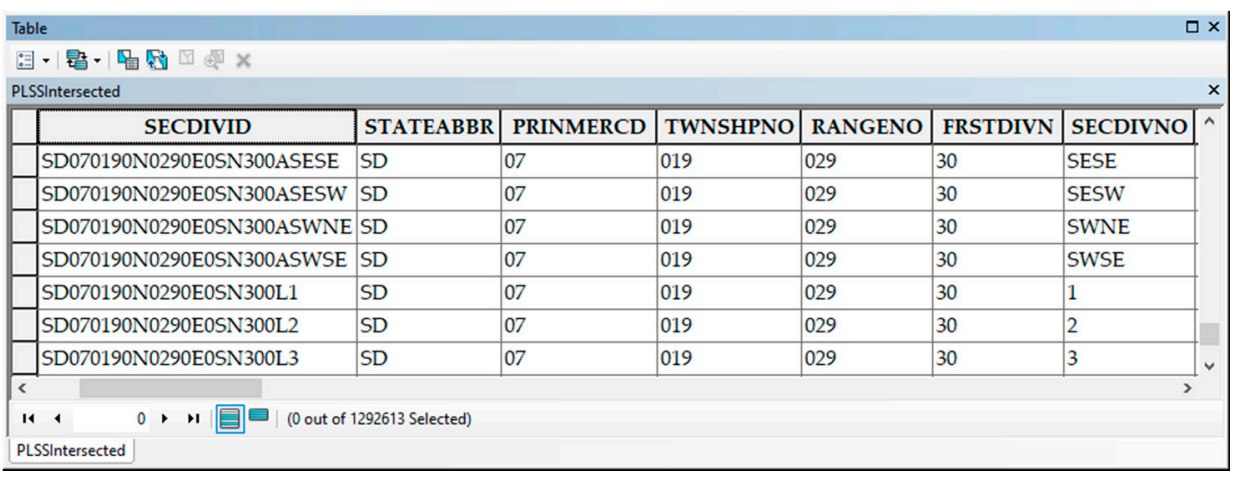

Figure 8. PLSS attribute table viewed in ArcGIS. SECDIVID (PLSS second division identification) field needs only slight modification to match the UID from the allotment ledger spreadsheet.

The allotment mapping tool first creates copies of original data files so as not to destroy source data, see step 1 of Figure 4. Blank attribute fields are generated for each possible parcel aliquot within a section in the attribute table of the downloaded PLSS Intersected GIS data (Table 1), see step 2 of Figure 4. A Field Calculation is performed by the GIS software, which essentially creates a modified SECDIVID field, and generates new unique IDs for each of the different aliquots in a section by modifying and concatenating field values, step 3 of Figure 4. PLSS features with the same unique ID are then spatially merged together generating new shapes for every possible land combination within a section, step 4 of Figure 4 . For example, an allotment may be described as the "western half of the southeast quarter of section 34, township 10, range 9." This particular unique ID for StandingRock would be SD0701000934WSE. This unique ID is generated by parsing through the attribute fields to extract the values needed, and then combining them back together. In the PLSS attributes the following field names are described: STATEABBR = State abbreviation, PRINMERCD = Principle Meridian Code, TWNSHPNO = Township number, RANGENO = Range number, FIRSTDIVNO = section number, and QQSEC = quarter-quarter section aliquot label. The following is an example Field Calculation that is used to generate unique identifiers for the eastern and western half-quarter sections, and see Table 2 for additional field calculation examples: [STATEABBR]\&[PRINMERCD]\&[TWNSHPNO]\&[RANGENO]\&[FRSTDIVNO]\&RIGHT([QQSEC], 3). For this particular example, the eastern and western half-quarter sections are created by simply removing the first letter, either an " $\mathrm{N}$ " or "S", from the quarter-quarter attribute values in the PLSS data (Figure 9). The RIGHT function is used here to truncate the quarter-quarter section aliquot description by returning three string characters from the right side of the QQSEC attribute, thus removing the first letter in the aliquot abbreviation and creating an aliquot description for the eastern/western half-quarter sections. This creates eight sets of duplicate unique IDs within the 16 quarter-quarters in a section, each of them either an eastern or western half of one of the four quarter sections. Dissolving boundaries in step 5 of Figure 4 uses matching unique IDs for all eight possible east/west half-quarter sections within a single section (Figure 10a-c). This process is repeated for each 
type of land description and merged together creating the master aliquot file Geodatabase of stacked and overlapping aliquot parcel shapes. The master aliquot can be imagined as a single stack of data layers, with each layer representing a different type of section aliquot from Table 1 all merged together in one comprehensive data file, (Figure 3).

Table 1. Possible aliquots within a section, size of each aliquot, and count per section and township.

\begin{tabular}{|c|c|c|c|c|c|}
\hline Section Aliquot & Example & Abbr. & Acres & Sections & Townships \\
\hline Half & Northern half & $\mathrm{N}$ & 320 & 4 & 144 \\
\hline Quarter & Southeast quarter & SE & 160 & 4 & 144 \\
\hline Half-half & Northern half of the northern half & $\mathrm{NN}$ & 160 & 8 & 288 \\
\hline Quarter-quarter & Southeast quarter of the northwest quarter & SENW & 40 & 16 & 576 \\
\hline Half-quarter & Northern half of the northwest quarter & NNW & 80 & 16 & 576 \\
\hline Half-half-quarter & Southern half of the northern half of the southeast quarter & SNSE & 40 & 32 & 1152 \\
\hline $\begin{array}{l}\text { Quarter-quarter-quarter } \\
\text { (QQQ) }\end{array}$ & $\begin{array}{l}\text { Southwest quarter of the northwest quarter of the } \\
\text { northeast quarter }\end{array}$ & SWNWNE & 10 & 64 & 2304 \\
\hline Half-quarter-quarter & $\begin{array}{c}\text { Southern half of the southeast quarter of the } \\
\text { northwest quarter }\end{array}$ & SSENW & 20 & 64 & 2304 \\
\hline Half-half-half-quarter & $\begin{array}{c}\text { Northern half of the southern half of the northern half of } \\
\text { the southeast quarter }\end{array}$ & NSNSE & 20 & 64 & 2304 \\
\hline Half-half-quarter-quarter & $\begin{array}{l}\text { Northern half of the southern half of the northwest quarter } \\
\text { of the south west quarter }\end{array}$ & NSNWSW & 10 & 128 & 4608 \\
\hline Half-QQQ & $\begin{array}{c}\text { Southern half of the northeast quarter of the northwest } \\
\text { quarter of the southwest quarter }\end{array}$ & SNENWSW & 5 & 256 & 9216 \\
\hline Half-half-QQQ & $\begin{array}{l}\text { Southern half of the southern half of the northeast quarter } \\
\text { of the southwest quarter of the southeast quarter }\end{array}$ & SSNESWSE & 2.5 & 512 & 18,432 \\
\hline
\end{tabular}

Table 2. Example Field Calculations performed in GIS on the PLSS Intersected base layer. This generates Unique IDs for various parcel aliquots. A dissolve function is later performed using the Unique IDs, thus generating the final parcel shape. This is step 3 in Figure 4.

\begin{tabular}{cc}
\hline Aliquot & Field Calculation \\
\hline Section & {$[$ STATEABBR] \& [PRINMERCD]\& [TWNSHPNO] \& [RANGENO] \& [FRSTDIVNO] } \\
\hline North/South Half & {$[$ STATEABBR] \& [PRINMERCD] \& [TWNSHPNO] \& [RANGENO]\& [FRSTDIVNO] \& LEFT([QSEC],1) } \\
\hline East/West Half & {$[$ STATEABBR] \& [PRINMERCD] \& [TWNSHPNO] \& [RANGENO] \& [FRSTDIVNO] \& RIGHT([QSEC],1) } \\
\hline North/South Half Half & {$[$ STATEABBR] \& [PRINMERCD]\& [TWNSHPNO] \& [RANGENO] \& [FRSTDIVNO] \& Left([QQSEC],1) } \\
\&Mid([QQSEC],3,1)
\end{tabular}




\begin{tabular}{|c|c|c|c|c|c|c|c|c|}
\hline \multicolumn{9}{|c|}{ Table } \\
\hline \multicolumn{9}{|c|}{ 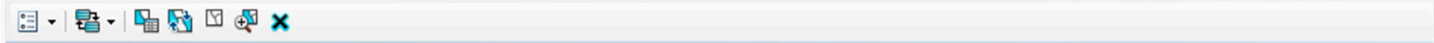 } \\
\hline \multicolumn{9}{|c|}{ PLSS_UID_Calculations } \\
\hline STATEABBR & PRINMERCD & TWNSHPNO & RANGENO & FRSTDIVNO & QQSEC & E/W Half Q Sect & UID E/W Half Quarter Sect & \\
\hline SD & 07 & 010 & 009 & 34 & NENW & ENW & SD0701000934ENW & \\
\hline SD & 07 & 010 & 009 & 34 & SWSE & WSE & SD0701000934WSE & \\
\hline SD & 07 & 010 & 009 & 34 & SENE & ENE & SD0701000934ENE & \\
\hline SD & 07 & 010 & 009 & 34 & SESE & ESE & SD0701000934ESE & \\
\hline $\mathrm{SD}$ & 07 & 010 & 009 & 34 & NWSE & WSE & SD0701000934WSE & \\
\hline SD & 07 & 010 & 009 & 34 & SWSW & WSW & SD0701000934WSW & $\checkmark$ \\
\hline \multicolumn{9}{|c|}{ 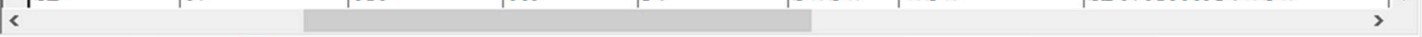 } \\
\hline \multicolumn{9}{|c|}{ 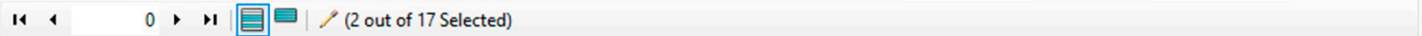 } \\
\hline \multicolumn{9}{|c|}{ PLSS_UID_Calculations | } \\
\hline
\end{tabular}

Figure 9. PLSS attribute table opened in ArcGIS. A field calculation in step 3 of Figure 4 is used to concatenate attribute values and generate Unique IDs. This example creates eastern and western half-quarter sections by removing the first character of the QQSEC field values, which are then concatenated together with other PLSS attributes to create the final aliquot Unique IDs. See Figure 8 for Field Calculation equation.

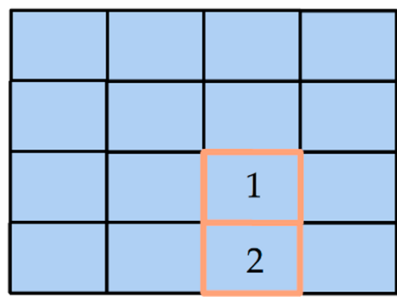

(a)

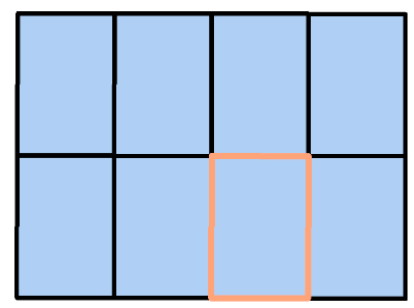

(b)

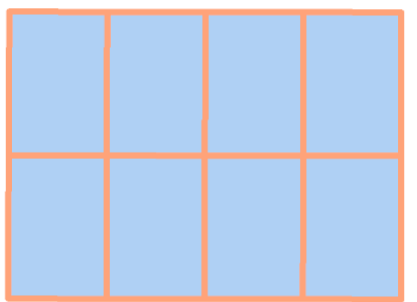

(c)

Figure 10. (a) The NW quarter of the SE quarter (1), and the SW quarter of the SE quarter section (2) are highlighted above and also in the attribute table in Figure 9. (b) The two quarter-quarter sections are merged together with the Dissolve tool, see step 4 of Figure 4. (b) The two quarter-quarter sections are merged together with the Dissolve tool, see step 4 of Figure 4. (c) For each section, 8 eastern/western half quarter sections are created. This is just one example of a typical land description. See Table 1 for other aliquot combinations.

For large reservations like Standing Rock, the master aliquot step requires a significant amount of computational time simply because of the large number of parcels generated in the master aliquot file. For example, when generating half sections, the GIS software creates 4 new spatial features for each section, each representing the four possible half sections (northern, southern, eastern, and western halves). When generating half-quarter sections, the software produces 16 new spatial features for each section. And, when generating half quarter-quarter sections, the software produces 64 new spatial features for each section. The Standing Rock reservation encompasses approximately 150 townships, or nearly 5400 sections, which makes generating the master aliquot a highly intensive computer process for larger reservations.

\subsubsection{Create the Allotment Parcel Database}

There currently are two primary ways to create an allotment parcel database. The first is to manually transcribe the handwritten allotment entries from the allotment ledger book for a reservation - either the allotment register or the allotment tract book can be used. The entries can be transcribed into Excel or any other spreadsheet or database that can be ingested into the GIS. It is important to record and store the information from the ledger books in the same schema used for the PLSS data, such as three-digit numbers for townships and ranges, and two-digit numbers for sections, government lots, and meridian codes. Aliquot descriptions in the allotment spreadsheets also must be standardized to match the PLSS nomenclature, such as SENW for the "southeast quarter of the northwest quarter section." The transcription process is laborious; depending on the size of the reservation and the number of allotments, hundreds of hours of labor may be required. 
Since the total number of data cells for a reservation's allotment database may reach into the tens of thousands, the possibility of inadvertent errors in transcription, especially errors in transcribing the PLSS information, is significant. Some errors can be detected rather easily by cross checking, while others may require an iterative process of mapping and correction.

The second method of creating a database of allotment parcels is to download all the allotment data for a reservation from the GLO website, which is the method used by Dippel et al. [29-31]. This method has the significant advantages of already having been checked for accuracy and being in the appropriate format for matching with the PLSS database. The GLO allotment data have three limitations, however. The first is that identifying all the allotment parcels for a given reservation is not always a straightforward process. Although the GLO land parcel online database has fields that can be useful for identifying allotment parcels, such as "Indian Allotment" and "Tribe," these fields are sometimes left blank or use a variety of terms rather than a single, uniform one. This means that it often is necessary to use a variety of search terms to obtain a complete dataset of allotments for a reservation. The second limitation of the GLO database is that, as noted earlier, it does not contain all the attribute information for allottees contained in the ledger books, e.g., age, marital status, sex, and family relationship, making it inadequate for performing numerous kinds of spatial analysis such as examining the spatial pattern of allotments within families or the relationship between allotments of husbands and wives or the distribution of allotments for adult women, to give just a few examples. The third limitation of the BLM/GLO database is that it only represents those tribal members who received patents for their allotments. In the case of Standing Rock, this represents nearly $99 \%$ of allottees, but this number varies from reservation to reservation.

As described above, allotment information for the Standing Rock reservation was photographed and transcribed from the allotment registers available at the Kansas City branch of the National Archives (Figure 11). These allotment registers contain information for the majority of Standing Rock allottees up until about 1910-11, a total of 4026 allotment recipients. However, allotments continued to be distributed up until allotment was ended in 1934. The remaining Standing Rock allottee information was obtained from the BLM/GLO website by querying the GLO Web Services for the unaccounted-for allottees between numbers 4027 to 4726 . A total of nearly 700 additional Standing Rock allottees were recorded between the end of the ledger books and the end of the allotment period in 1934. These 700 extra allottees received an additional 1095 parcels which were added to the parcels from the allotment register to create a complete dataset of the original allotments at Standing Rock.

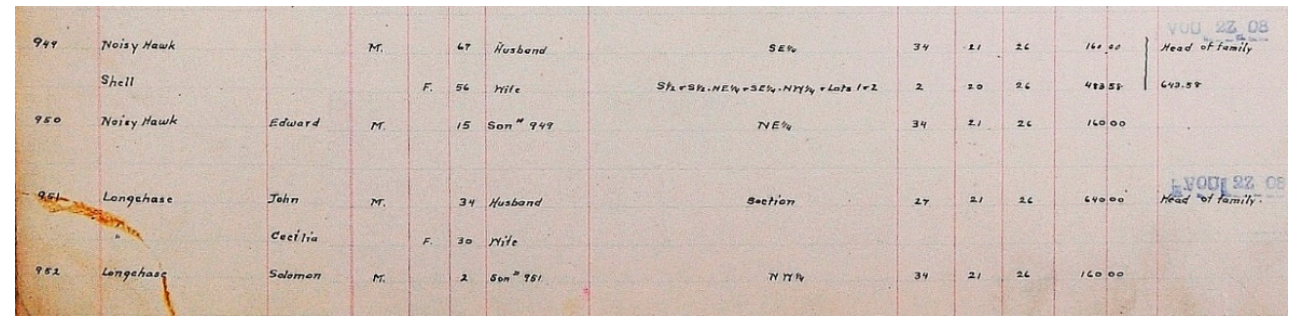

Figure 11. Sample image from the allotment ledger books, available from the National Archives. Note the variety of land descriptions in the middle column: one full section, one half-section, three quarter-sections, two quarter-quarter-sections, and two lots.

\subsubsection{Merge Matching Parcel IDs in the Two Databases to Create the Allotment} Spatial Database

The final step in creating the allotment mapping tool is to use a table join to match each spreadsheet allotment record's unique ID to a correct parcel in the "master aliquot." Each allotment record in the spreadsheet has a unique ID that perfectly matches one of the parcels contained in the "master aliquot." Only matching records are kept during the join, 
leaving only those parcels that are Indian allotments. In addition to automatically extracting the shapes of each parcel from the master aliquot, this join also adds the attribute data from the allotment spreadsheet, allowing for further analysis of the social demographic attribute data recorded in the allotment ledger books.

\subsubsection{Map the Few Remaining Non-Standard Parcels}

A validation process is performed after the initial allotment mapping tool is completed to determine which parcels in the spreadsheet were not mapped. This validation process, using a reverse join, matches the output of the allotment mapping tool back to the original spreadsheet, while keeping all unmatched records. This type of join will generate "Null" values for any unmatched records, and those records are then isolated and extracted. This creates a list of all allotment parcels that the tool could not map, and it can be then checked for transcription errors and other potential reasons why the tool failed.

After running the allotment parcel-mapping tool, there invariably will be a few parcels that remain unmapped. These consist of "micro-level" aliquots that are smaller than, or different from, the parcels in the master aliquot file, and non-standard parcels whose boundaries are expressed in metes-and-bounds descriptions rather than as aliquot subdivisions and thus cannot be mapped by the mapping tool. These problems are resolved using two different methods: (1) creating "micro" aliquot databases for remaining unmapped small aliquots and merging them into the allotment database and (2) manually digitizing the few remaining allotments that could not be mapped using the tool.

\section{Results}

The allotment mapping tool, using only the quarter-quarter section PLSS buildingblocks, produced 12,953 mapped parcels, or $97.2 \%$ of total allotment parcels $(13,324)$ (Table 3). After performing a validation check (see Section 2.2.4), the mapping tool produced a report of unmapped records from the original spreadsheet. At Standing Rock, only 371 parcels from the allotment ledger books could not be mapped by the tool at the quarter-quarter level. As noted above, these consisted of aliquots smaller than those in the master aliquot database or parcels expressed in non-aliquot terms, for example "the north 10 chains of Lot 4," or "From center of section 24, hence west 5 chains; 8 chains to river; southeast along river to line between SE4 of SW4; North to place of beginning." (One chain $=66$ feet in the U.S. survey system.)

Of the 371 remaining unmapped parcels, 251 were aliquot parcels but were smaller than the smallest parcel size in the master aliquot file and therefore required a modified PLSS building block to map. The quartering tool was used to split the sections containing unmapped parcels into quarter-quarter-quarter sections (10-acre aliquots) and quarterquarter-quarter-quarter sections (2.5-acre aliquots). Rather than doing this for the entire reservation area, only the specific section for each of the unmapped parcels was used by the quartering tool as a way to decrease unnecessary processing and therefore the time needed to generate these few, small-sized parcels. A second pass of the tool was then performed on these "micro" aliquots and they were added to the allotment map. This brought the total of successfully auto-mapped parcels to 13,204 or $99.1 \%$ (Table 3).

The remaining 120 parcels could not be drawn by the tool because they contain nonstandard land descriptions, as noted above. Ordinarily, all these parcels would need to be measured and drawn manually; however, at Standing Rock the majority of these parcels fortunately already exist in the PLSS data as newly renamed government lots. The GLO plat maps of Sioux County, North Dakota and Corson County, South Dakota (which comprise the Standing Rock Reservation) were used to verify these locations as well as extract the new PLSS government lot number. These were then merged with the allotment database, resulting in a final successful mapping rate of $99.7 \%$ using automated methods (Table 3). Only around two dozen of the last 120 parcels remained unmapped after this process, and they were manually digitized and merged with the allotment database. 
Table 3. Results of allotment mapping tool at Standing Rock. The vast majority of parcels can be mapped using only the quarter-quarter sections and government lots available in the PLSS Intersected data set. A modified quarter-quarter-quarter-quarter section file was generated on a second-pass of the tool to create the remaining small-area parcels. Manual digitization was only needed on less than 1 percent of the allotments on the reservation.

\begin{tabular}{ccc}
\hline Mapping Method & \# of Parcels Mapped & \% of Total \\
\hline Quarter-quarter PLSS & 12,953 & 97.22 \\
\hline Modified QQQQ PLSS & 251 & 1.88 \\
\hline Manual methods & 120 & 0.90 \\
\hline Total Parcels & 13,324 & 100.00 \\
\hline
\end{tabular}

In addition to successfully mapping nearly $100 \%$ of the allotment parcels at Standing Rock, the automated mapping tool created an allotment map with an unprecedented level of detail by mapping even the smallest aliquot parcels (Figure 12a,b). In their landmark studies, Dippel et al. claimed the ability to map $97.7 \%$ of all allotments at the quarter-section level of the PLSS [29]. It must be remembered, however, that their approach only mapped parcels at the quarter-section (160-acre) level, and did so by assigning parcels smaller than that size to the quarter section in which they lie (Figure 12a). The new allotment mapping tool easily generates these smaller sized allotment parcels, achieving a near-complete dataset of allotment for a reservation in a matter of hours. By using 160-acre parcels as base units, Dippel et al. overestimated the size of all allotments under 160-acres, and failed to produce spatial features for a large number of smaller allotments that were available from the BLM GLO database. The new allotment mapping tool has an advantage over these and other techniques because it accurately maps allotment parcels down to the finest aliquot, while automating the most time-consuming aspects.

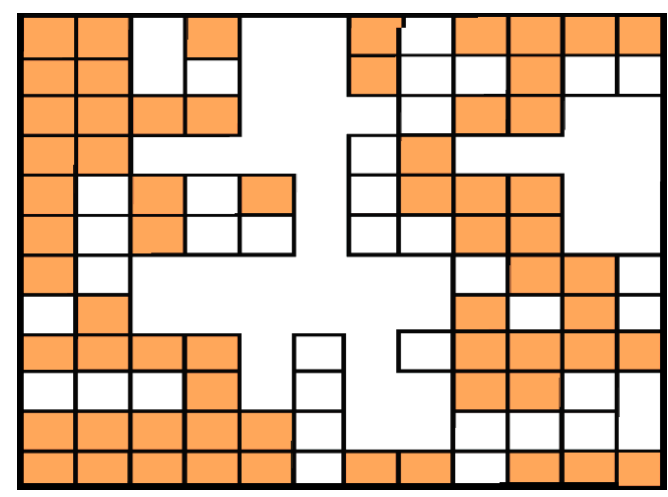

(a)

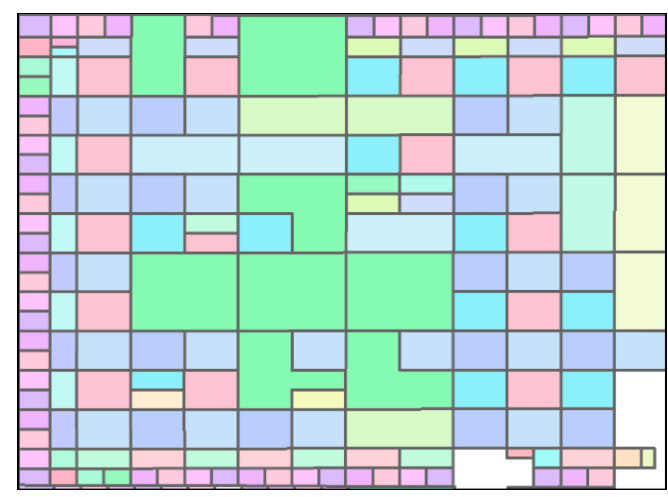

(b)

Figure 12. (a) Pine Ridge reservation allotment parcels adapted from Dippel et al. [29-31]. (b) The same area at Pine Ridge mapped using the new allotment mapping tool described in this study, random color scheme assigned by GIS software.

The spatial distributions of allotments at Standing Rock displayed in the preliminary maps reveal several interesting patterns. Based on previous studies of allotment, it was expected that the allotments at Standing Rock would roughly align with the spatial distribution of rivers and streams and their associated woodlands, and the map of allotments confirmed that this was the case (Figure 13). In addition to streams and rivers, lands near existing and proposed railroad lines were also heavily allotted, implying that connectivity, mobility, and proximity to resources that the railway would provide were important to at least some individuals when selecting their allotments. 


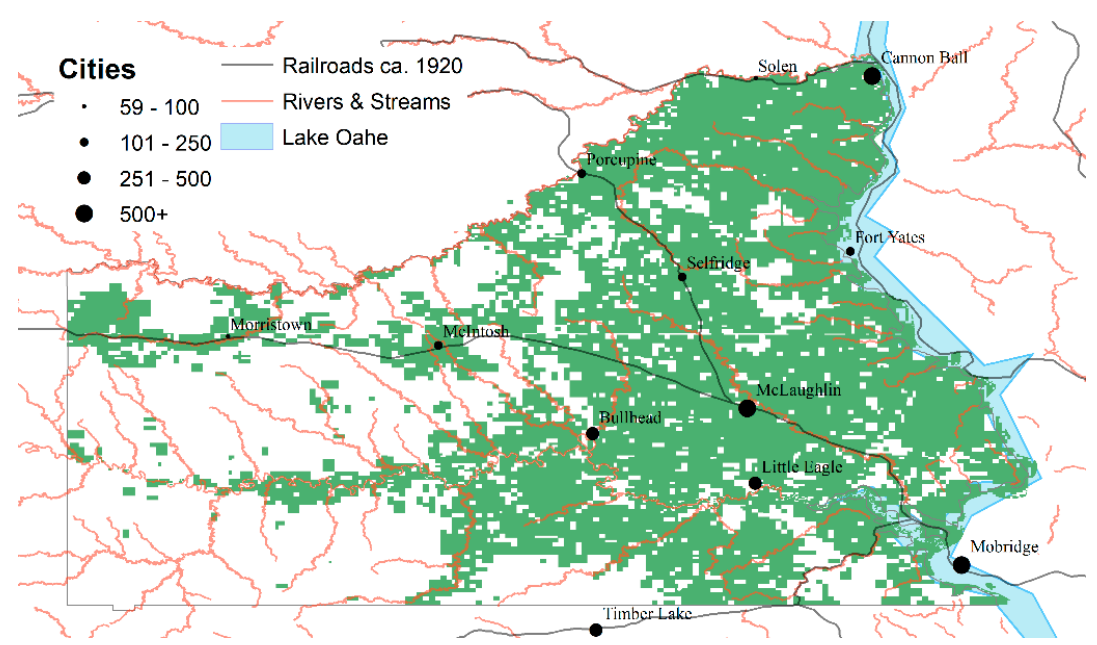

Figure 13. The overall allotment pattern at the Standing Rock reservation.

The spatial pattern of allotments also closely matches previously generated "surplus land" maps that were created in 1911 and 1925 by the Office of Indian Affairs (renamed the Bureau of Indian Affairs, BIA, in 1947) to aid non-Indian settlers in choosing available parcels on the newly opened reservation (Figure 14a-c). Despite Sutton's observation that Indian land maps can be unreliable since they are updated and modified so often, the surplus land maps and the allotment data line up quite well after overlaying them with the newly created allotment features.

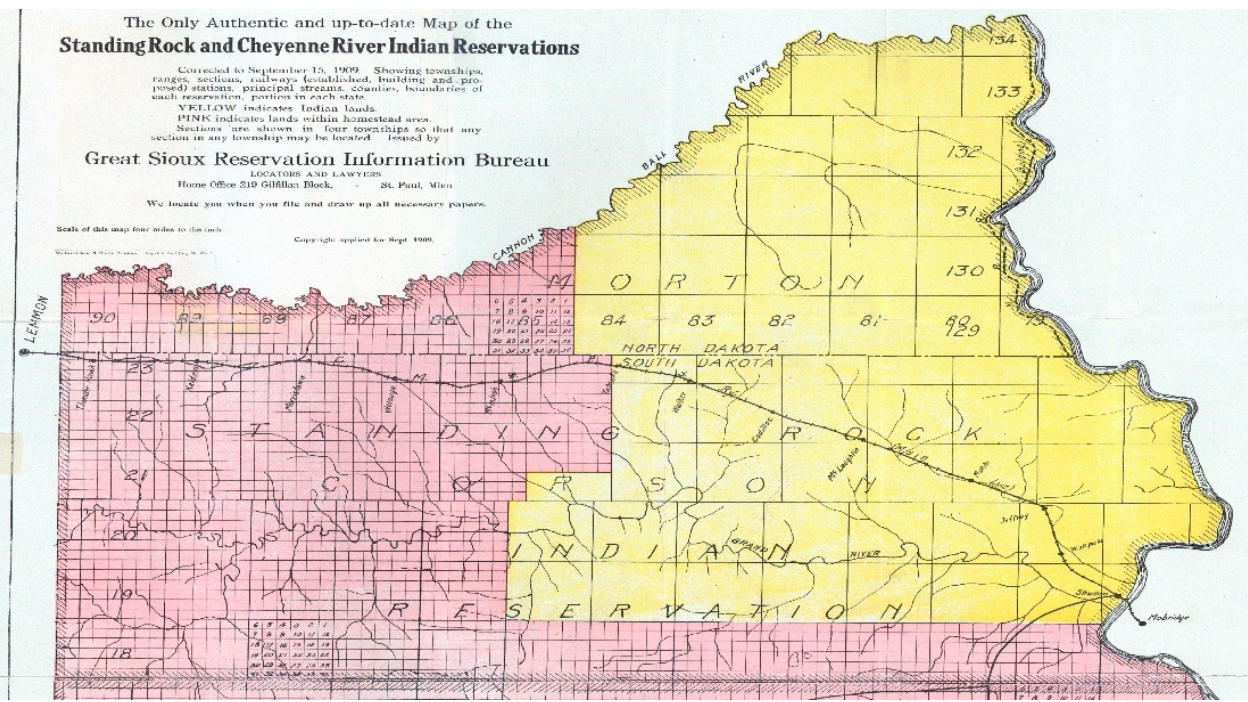

(a)

Figure 14. Cont. 


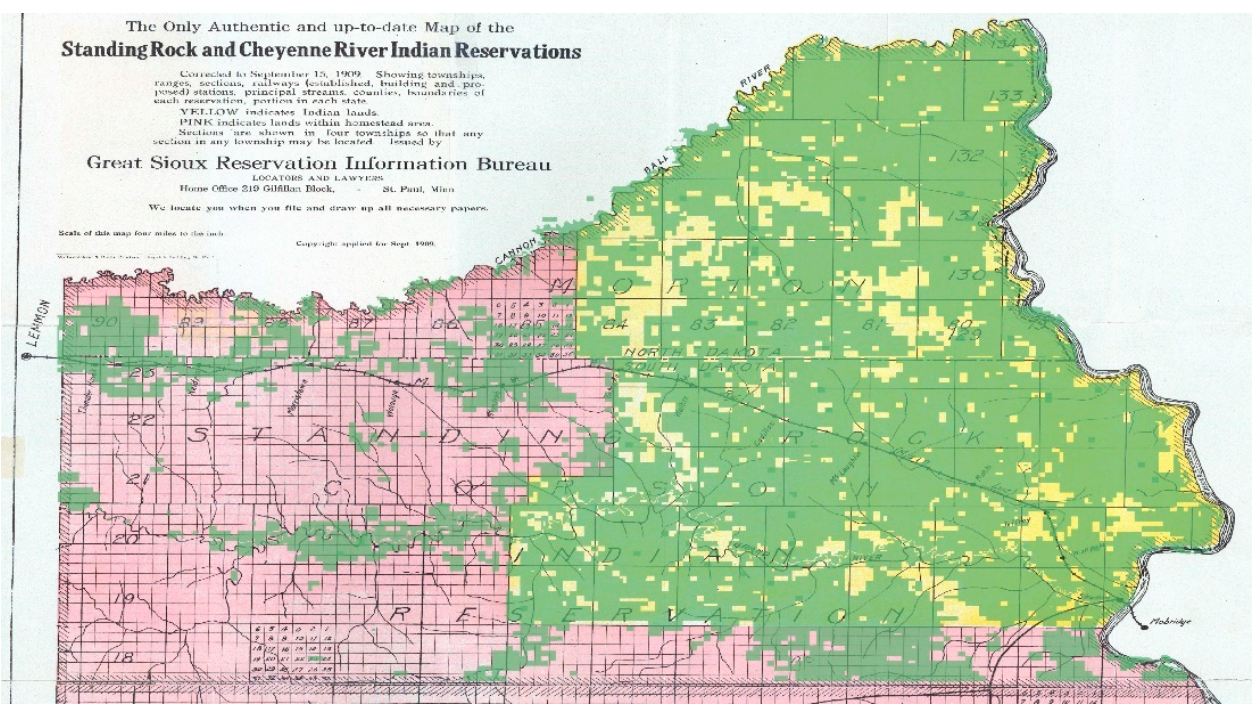

(b)

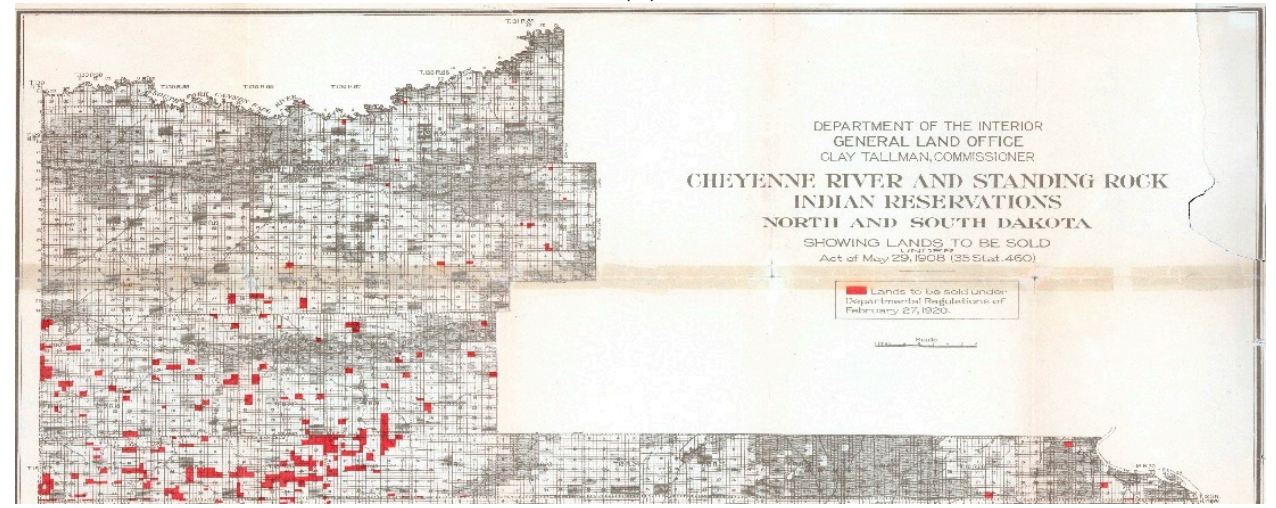

(c)

Figure 14. (a) 1909 map of surplus reservation lands available for sale to non-tribal members after allotment (pink) versus lands set aside for the tribe (yellow). (South Dakota State Historical Society Digital Archives: 2019-09-25-0004). (b) Allotments (green) overlaid on the map, confirming that the majority of land allotted on the reservation lies within the designated yellow area. (c)1920 map showing remaining surplus lands after allotment. Dark grey areas are allotments outside of the previously designated areas to the east. These areas match green areas in Figure 14b. (South Dakota State Historical Society Digital Archives: 2019-09-25-0006).

Since allotments were made sequentially by allotment number, it also is possible to examine the temporal patterns of allotment based solely on the allotment numbers and a knowledge of the allotment process at Standing Rock (Figure 15). One major temporal pattern shows that the special allotting agent began allotting parcels in the far southeast corner of the reservation first and worked methodically across the reservation in tiers, with later allotments further west and north.

A second spatio-temporal pattern focuses on the relative locations of allotments between two groups of allottees. In practice, there were two waves of allotment at Standing Rock. The first wave began in 1906 and was completed with individual allottee number 2495, sometime in 1908 or 1909 . These allotments were made to all those who were authorized to receive allotments under the initial enabling act. However, as noted earlier, in 1906 the married women of Standing Rock and other Sioux reservations petitioned for their own allotments, separate from their husbands, which they later received during a second wave of allotment [33]. In addition, children born during the initial wave of allotments were also awarded allotments during this later period. The spatial patterns in Figure 14 illustrate this complex process. Since the majority of allotments in the first wave were located in the eastern part of the reservation, there were relatively few remaining 
parcels in that region, meaning that many of the married women and unallotted children of the second wave were forced to select lands further to the west. This pattern is visible in Figure 15. Although a few of the second-wave allottees (allotment numbers 2496 through 4726) were able to select scattered parcels in the east (and presumably closer to parcels selected by their husbands or other allotted family members), the vast majority of these lands were located to the west of those in the first wave.

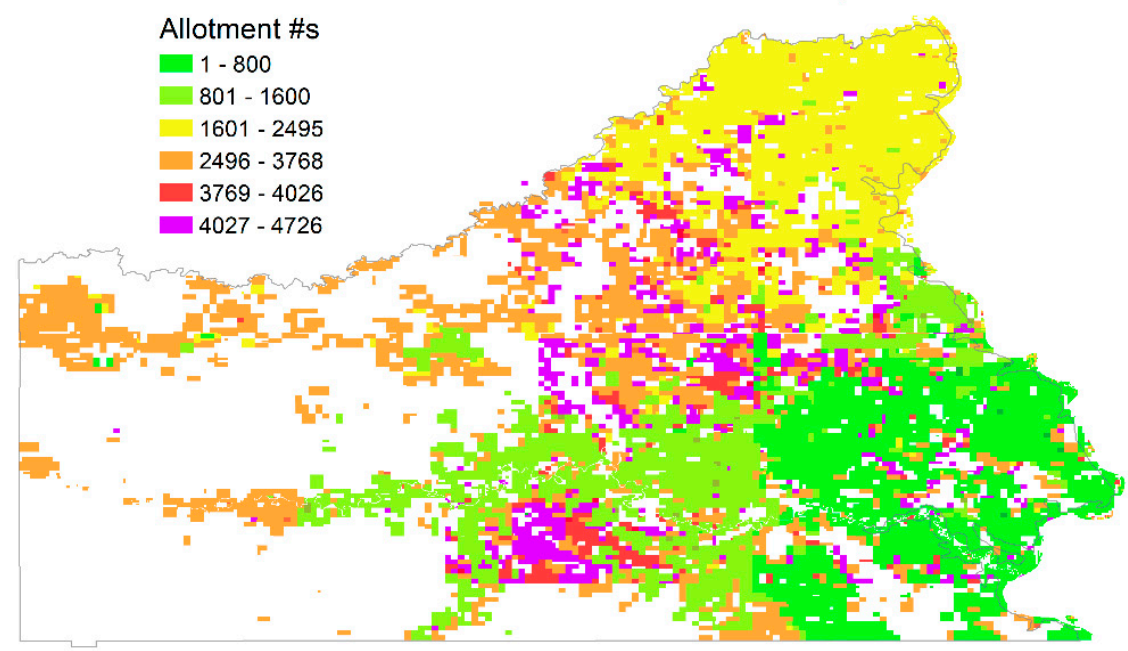

Figure 15. Categorized allotment data based on allotment number. The pattern illustrates the temporal progress of allotment across the reservation as it spreads from the southeast corner.

\section{Discussion}

\subsection{Significance of this Research-A Tool to Extend Tribal Sovereignty}

Access to accurate data has been and continues to be of paramount importance for American Indians. The work to understand individual Indian's land ownership and property rights and thus the residual effects stemming from allotment land is a complex undertaking and access to data is key. This GIS tool opens up the possibility for each tribe to map its historical allotments, at least where the data are available. The BLM/GLO has near-complete allotment data for 124 out of 326 current federally recognized Indian reservations, and it also has a significant amount of uncategorized allotment data, where tribal affiliation or allotment number was not recorded.

Data sovereignty, or the control of data that helps individual Indians understand these rights, is a burgeoning topic regarding tribal lands and was a central tenet of the largest class action lawsuit filed and successfully decided in favor of individual Indians. In Cobell v. Salazar (2009), Eloise Cobell, a member of the Blackfeet Nation in northern Montana brought a class action lawsuit against the Department of Interior (DOI) representing individual Indian land owners. Cobell asked the DOI for an accurate accounting of individual Indian moneys generated by leasing and extraction of resources such as gas and oil from individual allotment lands, but the DOI was unable to produce an accurate accounting of nearly 130 years of residuals and the case was settled at $\$ 3.4$ billion. In the process of the lawsuit, the flaws of allotment, i.e., fractionation and the deficiencies in the trust relationship, further came to light. Cobell $v$. Salazar illustrates the need for tribes to be able to be transparent stewards of their own land data and records and not rely solely on the federal government for this information. Work is already underway to map the available BLM/GLO allotment records and make the data available to the tribes. Organizations such as Indian Land Tenure Foundation, Village Earth, Indian Agriculture Council, Native American Agriculture Fund, and a handful of interested parties are working with tribes and other agencies to make this a reality. This tool can be a significant building block for achieving those goals. 


\subsection{Potential Improvements to the Mapping Tool and Its Databases}

The GIS methods used here to automatically generate spatial data from text-based land descriptions has room for optimization. This is an early version of the tool that was created to verify that it works on multiple different reservations and, so far, it has performed as expected. However, large reservations are difficult to map without splitting up the reservation into smaller units for processing. The creation of the master aliquot data file is arguably the most computationally intensive process and has the most potential for improvement. Generating millions of parcels only to select a few and delete the rest seems wasteful. On the Standing Rock reservation, most of the smallest parcels that required the most computation time were grouped together in only a select number of sections. Isolating these sections for separate processing decreased the time needed to generate these smaller aliquots, but there are potentially other ways to speed up processing time. In addition, future versions of the tool will be modified to run in ArcGIS Pro. ArcGIS Pro is a 64-bit software, while ArcMap is 32-bit, which should speed up the mapping processes significantly. It also is anticipated that future versions will be ported to $\mathrm{R}$ and Python for those not using ESRI software products.

It was noted earlier that each of the two major sources of allotment data (archival ledgers and the BLM/GLO database) has its strengths and weaknesses. Although the BLM/GLO online datasets offer the clear advantages of being accurate and ready to ingest into the tool, they lack important attribute information that is critical for certain types of spatial analysis. One solution to the problems associated with each of the methods of creating a database of allotment parcels is to begin by downloading the digital allotment data from the BLM/GLO website and then filling in its missing fields (age, marital status, etc.) with information found in the archival allotment ledgers. This could be further added to, if desired, by entering information found on land patents, leasing records, Indian censuses, and others. This method would have the advantage of beginning with a spatial database of parcels that already is correct and complete (or nearly so) and augmenting it with attribute data fields that are necessary for performing spatial analyses of the type needed for more fully understanding the impacts of allotment.

\subsection{Future Avenues of Research at Standing Rock}

There is still much work to be done to fully understand how the process of allotment played out at the Standing Rock Reservation. Now that spatio-demographic data are available for the reservation, further analysis of the policy, practices, and patterns of allotment at the reservation can be performed. For example, since transportation and connectivity seemed to be important in the preliminary analysis of the allotment map, it would be interesting to add known wagon trails, dirt roads, and highways to the transportation layer. GIS could be used to calculate the distance from each allotment to existing roads, rivers, and railways, and then test these measures for statistical significance.

Pre-allotment settlement patterns were discussed by Indian agents at Standing Rock in their annual reports, which confirmed that the reservation was largely settled prior to the allotment era, with families self-allotting on personal plots of land. One spatial pattern that deserves further exploration is that of family connections, as family relationships, both in the nuclear and extend family, were extremely important to tribal members. It will be recalled that the Standing Rock allotment ledgers recorded information about families and about how each allottee was related to the head of the family. This information can be mapped and analyzed to answer questions about what allotment strategies family members might have used in selecting allotments? Did they select allotments that were adjacent to each other where possible, or did they put primary emphasis on selecting the best available lands (e.g., those with access to water), perhaps resulting in more dispersed patterns? Preliminary exploration at Standing Rock appears to indicate that allotments of related family members exhibited a wide variety of patterns (Figure 16). 


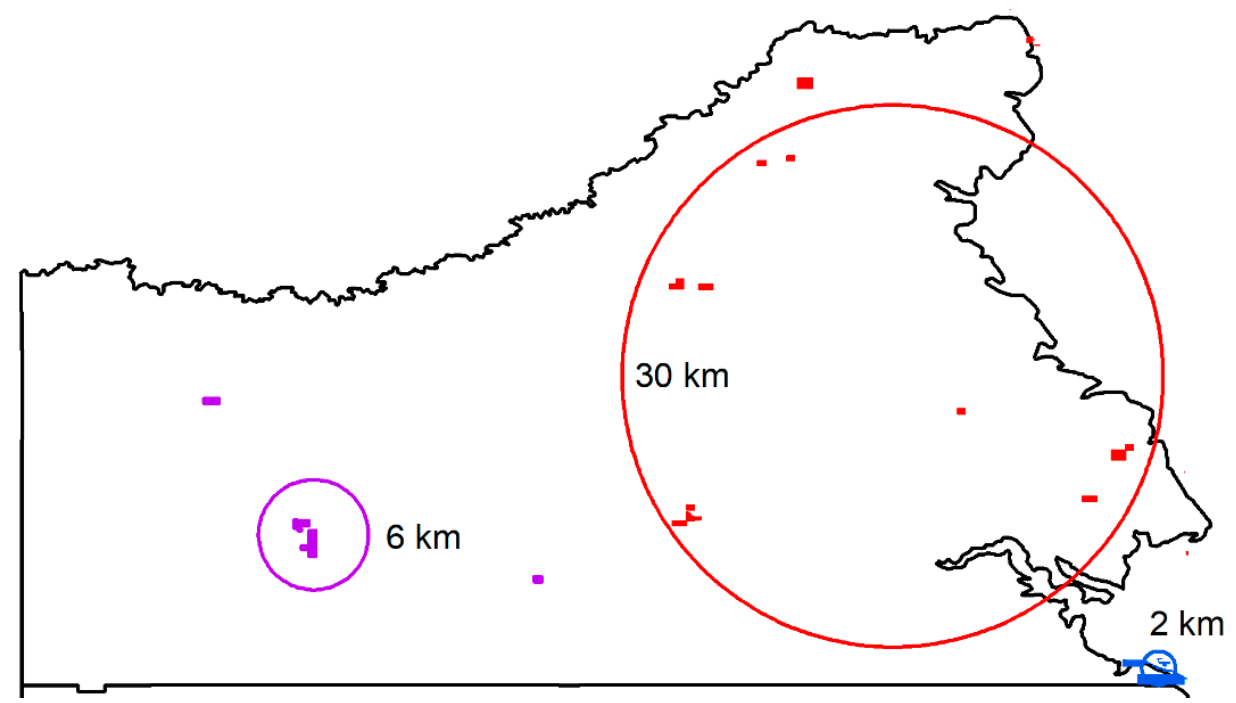

Figure 16. Spatial patterns of three different Standing Rock families in purple, blue and red. The circles are Standard Distances, or a measure of dispersion around a geometric mean center of these family allotments. Some families received allotments in clusters, in blue and purple, and other families were widely dispersed, in red.

A related question focuses on group settlement patterns within the reservation. As with several reservations, multiple groups were settled on the Standing Rock reservation. The four different Lakota and Dakota bands living at Standing Rock by the time of allotment were the Hunkpapa, Sihasapa (Blackfeet), Lower Yanktonai, and Upper Yanktonai. Indian agents noted that they settled separately in rough spatial groups, which would align with similar clan or tribal settlement patterns found on the Cheyenne, Pawnee, Nez Perce, and other reservations. It would be possible to map allotments by band affiliation by combining allotment data with information found in several of the annual Indian censuses taken by the Office of Indian Affairs that contain band affiliation information for the Standing Rock reservation. Each of the four Lakota/Dakota bands on the reservation was surveyed separately for a number of different years in the late 1890s. In addition, some Indian censuses in the 1920s and 1930s also recorded allotment and annuity numbers for each tribal member. Names from these Indian censuses could be used to crosscheck and update each allottee's tribal affiliation in the GIS data.

Ultimately, the story of allotment is one of land dispossession, as million acres of tribal land were lost as a result of this failed assimilation policy. A question remains as to how many acres of land were allotted at Standing Rock to tribal members, how many acres were sold as surplus, and how much Indian and tribally owned land is left today? Quantifying and visualizing the dispossession of Indian lands is core to understanding the scope of how the Dawes Act affected and affects reservation life. County atlases and modern land tax parcels can be used in conjunction with the digital allotment database to update the status of the original allotments - to determine if they have been sold or leased to non-tribal members, purchased by the tribe, or remain in trust status.

\subsection{A Framework for Future Research on the Spatio-Temporal Impacts of Allotment}

Each Indian reservation had the Dawes Act applied to it differently, resulting in a variety of different outcomes that need to be explored. However, the process of mapping allotment data and the ability to spatially analyze the data in GIS has been proven to be fundamental to the future of allotment research. The subject of the impacts of Indian land allotment policy is largely a spatial issue, and geographic information systems provide a framework, methodologies, and toolsets to answer many of the remaining questions about allotment. Toward that end, seven broad categories of questions initially suggest themselves for GIS mapping, visualization, and analysis: 
1. Overprinting. When allotment came to a reservation, it was almost always the case that its Native residents already had long resided there, in some cases for decades or longer, and had established well-defined patterns of residency and land use. Thus, allotment's rectangular grid survey system was overlaid on top of the existing pattern of land tenure, a process sometimes referred to as overprinting, resulting in potential disruption and conflicts. How do mapped patterns of allotment represent the impacts of overprinting and of efforts by both allotting agents and allotment recipients to resolve them?

2. Environmental factors. Each reservation was characterized by a unique combination of physical environmental factors, including climate, vegetation, soils, wild game and other animals, hydrology, and others that varied in quality and quantity across the reservation. When allottees (or sometimes the allotting agent) made land selections, what factors were considered most desirable or, conversely, least desirable?

3. Social factors. As noted above, prior to allotment Native people were often long settled on their reservations according to well-established patterns of social relationships and residency. In making allotment selections, did people maintain those patterns by selecting allotments close to other family members, friends, or clan groups? Or, conversely, did they avoid certain groups?

4. Economic factors. Did allotment recipients favor locations that gave them access to towns or trading centers or to transportation routes such as rivers, trails or roads, and prospective or existing railroad lines? Likewise, did they select allotments near to agency or subagency locations, or to existing or planned schools and churches?

5. Impacts of local allotment policies. Although Congress set broad guidelines for allotting each reservation, the local special allotting agent had considerable leeway in setting detailed on-the-ground policies for allotments. How did those policies reveal themselves in observed patterns of allotment? For example, were allottees encouraged, or perhaps forced, to take their allotment as a single parcel or could they select multiple parcels and, if so, how many and of what sizes, and where? How were conflicts over desired allotment parcels settled among contending allottees? And what was done in the case of individuals who refused to accept allotments?

6. Post-allotment policy changes. After allotment, and even while it was still ongoing, the defects of allotment became glaringly apparent. Numerous, sometimes bewildering, policies regarding inheritance, land leasing, land sales, and fraud prevention, among others, were implemented, modified, and then modified again in vain attempts to prevent loss of land and to shore up the original goals of turning American Indians into successful farmers and ranchers. How did these various policies impact land holding (or land loss), land management, and even patterns of living?

7. Long-term broad impacts. How can the impacts of fractionation, checkerboarding, land loss, widespread land leasing to non-Native farmers and ranchers, and other widespread results of allotment be represented and explored in spatial datasets?

This framework is merely a starting point, and we anticipate that other sets of questions will be added as our research continues.

The new mapping tool described here provides a way to rapidly and accurately produce high quality spatial data of Indian allotment lands on reservations, data that are important to tribal members and future generations. It allows for the creation of this same dataset, not only for the Standing Rock reservation, but many other reservations across the United States that underwent allotment. Currently work is underway to establish partnerships with Native American and tribal non-profit organizations to continue this work and make training and data available to tribal land offices and the general tribal communities. Baseline datasets are necessary to answer a large range of questions, and this research provides that essential first step. It is difficult to ask and answer questions without available data. This allotment mapping technique will allow tribal members and researchers access to accurate spatial data for their reservation lands. 
Author Contributions: Conceptualization, Joshua Jerome Meisel; data curation, Stephen L. Egbert; formal analysis, Joshua Jerome Meisel; funding acquisition, Stephen L. Egbert and Joseph P. Brewer II; investigation, Joshua Jerome Meisel; methodology, Joshua Jerome Meisel; resources, Stephen L. Egbert; visualization, Joshua Jerome Meisel; writing—original draft, Joshua Jerome Meisel, Stephen L. Egbert and Joseph P. Brewer II; writing-review and editing, Stephen L. Egbert, Joseph P. Brewer II and Xingong Li. All authors have read and agreed to the published version of the manuscript.

Funding: The authors gratefully acknowledge funding from the Indian Land Tenure Foundation, grant numbers ILTF20151015, ILTF 20170101, and from the General Research Fund of the University of Kansas, grant number 2301149. APC was funded by Haskell Indian Nations University, NSF EPSCoR grant number OIA-1656006.

Institutional Review Board Statement: Not applicable.

Informed Consent Statement: Not applicable.

Data Availability Statement: The mapping tool and sample data are available to download www. haskellgeography.com (accessed on 10 March 2021).

Acknowledgments: The authors wish to acknowledge the work of Chelsea Burgess, Ximena Sevilla Benavides, and Cheyenne Sun Eagle in transcribing archival records.

Conflicts of Interest: The authors declare no conflict of interest. The funders had no role in the design of the study; in the collection, analyses, or interpretation of data; in the writing of the manuscript, or in the decision to publish the results.

\section{References}

1. United States Census Bureau. Small Area Income and Poverty Estimates Program (SAIPE). Available online: https://www. census.gov/programs-surveys/saipe.html (accessed on 10 March 2021).

2. An Act to Provide for the Allotment of Lands in Severalty to Indians on the Various Reservations (General Allotment Act or Dawes Act), Statutes at Large 24, 388-91, NADP Document A1887. Available online: https:/ /www.ourdocuments.gov/doc.php? flash $=$ false \&doc $=50 \&$ page $=$ transcript (accessed on 10 March 2021).

3. United States. Papers Relating to the Foreign Relations of the United States, with the Annual Message of the President Transmitted to Congress December 3, 1901; United States Government Publishing Office: Washington, DC, USA, 1902. Available online: https: / / play.google.com/books/reader?id=sL40AQAAMAAJ\&pg=GBS.PR9 (accessed on 10 March 2021).

4. McDonnell, J.A. The Dispossession of the American Indian, 1887-1934; Indiana University Press: Bloomington, IN, USA, 1991; ISBN 0253336287.

5. Royster, J. The Legacy of Allotment. Ariz. State Law J. 1995, 27, 1-78.

6. Shoemaker, J.A. Like Snow in the Spring Time: Allotment, Fractionation, and the Indian Land Tenure Problem. Wis. Law Rev. 2003, 4, 729-788.

7. Banner, S. How the Indians Lost Their Land: Law and Power on the Frontier, 1st ed.; The Belknap Press of the Harvard University Press: Cambridge, MA, USA, 2005; ISBN 067402396X.

8. Hoxie, F.E. A Final Promise: The Campaign to Assimilate the Indians, 1880-1920, 1st ed.; University of Nebraska Press: Lincoln, NE, USA, 1984; ISBN 0803273274.

9. Otis, D.S. The Dawes Act and the Allotment of Indian Lands, 1st ed.; University of Oklahoma Press: Norman, OK, USA, 1973; ISBN 0806110392.

10. Prucha, F.R. The Great Father: The United States Government and the American Indians, 1st ed.; University of Nebraska Press: Lincoln, NE, USA, 1986; ISBN 0803287127.

11. Debo, A. And Still the Waters Run: The Betrayal of the Five Civilized Tribes, Revised ed.; Princeton University Press: Princeton, NJ, USA, 1973; ISBN 0691005788.

12. Gates, P.W. Fifty Million Acres: Conflicts over Kansas Land Policy, 1854-1890, 1st ed.; Cornell University Press: Ithaca, NY, USA, 1954.

13. Wishart, D.J. An Unspeakable Sadness: The Dispossession of the Nebraska Indians, 1st ed.; University of Nebraska Press: Lincoln, NE, USA, 1995; ISBN 080324774.

14. Greenwald, E. Reconfiguring the Reservation: The Nez Perce, Jicarilla Apaches, and the Dawes Act, 1st ed.; University of New Mexico Press: Albuquerque, NM, USA, 2002.

15. Tonkovich, N.T. Dividing the Reservation: Alice C. Fletcher's Nez Perce Allotment Diaries and Letters, 1889-1892, 1st ed.; Washington State University Press: Washington, DC, USA, 2016; ISBN 9780874223446.

16. Sutton, I. Cartographic Review of Indian Land Tenure and Territoriality: A Schematic Approach. Am. Indian Cult. Res. J. 2002, 26, 63-114. [CrossRef]

17. Hoffmeister, H. The Consolidated Ute Indian Reservation. Geogr. Rev. 1945, 35, 601-623. [CrossRef]

18. Moore, J.H. Aboriginal Indian Residence Patterns Preserved in Censuses and Allotments. Science 1980, 207, 201-202. [CrossRef] [PubMed] 
19. Middleton, E.R. Seeking Spatial Representation: Reflections on Participatory Ethnohistorical GIS Mapping of Maidu Allotment Lands. Ethnohistory 2010, 57, 363-387. [CrossRef]

20. Greenwald, E. Allotment in Severalty: Decision-Making during the Dawes Act Era on the Nez Perce, Jicarilla Apache, and Cheyenne River Sioux Reservations. Ph.D. Thesis, Yale University, New Haven, CT, USA, 1994.

21. Greenwald, E.; Historical Research Associates, Inc., Missoula, MT, USA. Personal communication, 2020.

22. Palmer, M. Sold! The Loss of Kiowa Allotment in the Post-Indian Reorganization Era. Am. Indian Cult. Res. J. 2011, 35, 37-57. [CrossRef]

23. Kretlzer, I. Archives of Native Presence: Land Tenure Research on the Grand Ronde Reservation. Am. Indian Cult. Res. J. 2017, 41, 45-70. [CrossRef]

24. Kretzler, I. An Archaeology of Survivance on the Grand Ronde Reservation: Telling Stories of Enduring Native Presence. Ph.D. Thesis, University of Washington, Seattle, WA, USA, 2019.

25. Egbert, S.; Smith, P. "Great Frauds and Grievous Wrongs": Mapping the Loss of Kickapoo Allotment Lands. In Native American Symposium, Representations and Realities; Southeastern Oklahoma State University: Durant, OK, USA, 2017.

26. Allen, A.G. Allotting the Omaha Reservation: Patterns and Impacts, 1884-1940. Ph.D. Thesis, University of Kansas, Lawrence, KS, USA, 2019.

27. Eagle, C.S. Spatial and Temporal Patterns of Land Allotment on the Pawnee Reservation. Master's Thesis, University of Kansas, Lawrence, KS, USA, 2020.

28. Dippel, C.; Frye, D. The Effect of Land Allotment on Native American Households during the Assimilation Era. Available online: https://www.cgm.pitt.edu/sites/default/files/PPE/S20PPE/dawes_master-trim.pdf (accessed on 10 March 2021).

29. Dippel, C.; Frye, D.; Leonard, B. The Costs of Fractionated Land-Ownership: Evidence from Indian Land Allotment. Available online: https: / pdfs.semanticscholar.org/a017/b8310e9297b2fac9935464a03fd7a8f624b6.pdf (accessed on 10 March 2021).

30. Dippel, C.; Frye, D.; Leonard, B. The Costs of Tenancy in Common: Evident from Indian Land Allotment. Available online: https:/ / www.hoover.org/sites/default/files/dippel_frye_leonard.pdf (accessed on 10 March 2021).

31. Dippel, C.; Frye, D.; Leonard, B. Property Rights without Transfer Rights: A Study of Indian Land Allotment. Available online: https:/ / www.nber.org/papers/w27479 (accessed on 10 March 2021).

32. United States Congress. An Act to Divide a Portion of the Reservation of the Sioux Nation of Indians in Dakota into Separate Reservations and to Secure the Relinquishment of the Indian Title to the Remainder, and for Other Purposes. 1889. Available online: https://www.loc.gov/law/help/statutes-at-large/50th-congress/session-2/c50s2ch405.pdf? _cf_chl_captcha_tk_=97d274e5c3a7aa6e28279cd578271d3a8dda2071-1616219750-0-AQx1SSmRhA-4SM3FSdnhOkJHm1 1rHvRSJopNA493gkWP-Is-sR4VuKs6JJVIDBGwiU81MiXv5byXHNBwJr9VgDNqO6ynb_3hankPt62DtmGsxqCC91Uog_n2b_ OAlOrmx-DBx4yujzrgXPaSgxqqkVaiLicG7yewKNKmDSIbHiUmLk48N4PCp2y9RhvljPBry_nElxZ86U0BXONXugn9cTambf6 Xy6ZqZM4QLACTtqeSq7L4davrDV63NxIhDdG1J9Z_2MC42tNglagy9SuLyHW1QMnNHbBOGrmUFVMGskZ-h1bIooqr4 zt6EkJBcrtrMFmcoaYHQMwOMK4tGv2IlvdmLmiO4mtVpGWO_1B2aS6q0yaBhq61A0FGPAjOu-57kEuWTiy9wh1n6RV0 Wr6Y6Rvm8XNqOY9RFBq8SwpD2x3_1DplulivQ8JhzNlfS7PRlgY1H_jz1DusZYavAN89dN8jXbgeVHo8oZ2w19CxY9fKSmj1 qAmQtZsaAV618Qx_L64VdxuEgTHmTfSEO1hQpS-fcWiPopHsNn6s42uq5LjhUG9nVSTDYZjshD-7CeluJZtB-2XpXBXjgVaP1 P3sgwx1XeJ8clLnwHrzIp_F270gVpBHffPc0dN659iUpa_oxA (accessed on 10 March 2021).

33. United States Congress. Allotment of Lands to Married Women on Certain Indian Reservations. In H.R. Doc. No. 257, 59th Congr, 2nd Sess.; 1906.

34. Walls, M.D. Rediscovery of a Native American Cultural Landscape: The Chickasaw Homeland at Removal. Ph.D. Thesis, University of Kentucky, Lexington, KY, USA, 2015.

35. Byrnes, G. Boundary Markers: Land Surveying and the Colonisation of New Zealand, 1st ed.; Bridget Williams Books: Wellington, New Zealand, 2001; ISBN 9781877242908.

36. Thinking Spatially. Available online: http://ianbroad.com/ (accessed on 7 October 2020). 